\title{
Improvement of the Planting Method to Increase the Carbon Reduction Capacity of Urban Street Trees
}

\author{
Jin-Young Kim ${ }^{1}$, Hyun-Kil Jo ${ }^{2 *}$, and Hye-Mi Park ${ }^{1}$ \\ ${ }^{1}$ Lecturer, Dept. of Ecological Landscape Architecture Design, Kangwon National University, Chuncheon 24341, Republic of Korea \\ ${ }^{2}$ Professor, Dept. of Ecological Landscape Architecture Design, Kangwon National University, Chuncheon 24341, Republic of Korea
}

\section{ABSTRACT}

Background and objective: Urban street trees play an important role in carbon reduction in cities where greenspace is scarce. There are ongoing studies on carbon reduction by street trees. However, information on the carbon reduction capacity of street trees based on field surveys is still limited. This study aimed to quantify carbon uptake and storage by urban street trees and suggest a method to improve planting of trees in order to increase their carbon reduction capacity.

Methods: The cities selected were Sejong, Chungju, and Jeonju among cities without research on carbon reduction, considering the regional distribution in Korea. In the cities, 155 sample sites were selected using systematic sampling to conduct a field survey on street environments and planting structures. The surveyed data included tree species, diameter at breast height (DBH), diameter at root collar (DRC), height, crown width, and vertical structures. The carbon uptake and storage per tree were calculated using the quantification models developed for the urban trees of each species.

Results: The average carbon uptake and storage of street trees were approximately $7.2 \pm 0.6 \mathrm{~kg} / \mathrm{tree} / \mathrm{yr}$ and $87.1 \pm 10.2 \mathrm{~kg} / \mathrm{tree}$, respectively. The key factors determining carbon uptake and storage were tree size, vertical structure, the composition of tree species, and growth conditions. The annual total carbon uptake and storage were approximately 1,135.8 tons and 22,737.8 tons, respectively. The total carbon uptake was about the same amount as carbon emitted by 2,272 vehicles a year. Conclusion: This study has significance in providing the basic unit to quantify carbon uptake and storage of street trees based on field surveys. To improve the carbon reduction capacity of street trees, it is necessary to consider planning strategies such as securing and extending available grounds and spaces for high-density street trees with a multi-layered structure.

Keywords: carbon uptake, carbon storage, greenspace structure, planting guidelines, landscape tree

\section{Introduction}

The global society is currently implementing various policies and agreements to mitigate climate change such as heat waves, droughts, and floods caused by increased $\mathrm{CO}_{2}$ concentrations. Korea has also established the National Greenhouse Gas Emissions Reduction Roadmap and the $2^{\text {nd }}$ Basic Plan for Climate Change Response, setting the target to reduce greenhouse gases by $37 \%$ from the emissions forecast by 2030 (Ministry of Environment, 2016). Atmospheric $\mathrm{CO}_{2}$ is a major substance that takes up at least $60 \%$ of greenhouse gases that cause climate change (KMA, 2020), and it has been a subject of focused research worldwide. The average annual $\mathrm{CO}_{2}$ concentration on Earth is 410.5 ppm as of 2019, showing a $48 \%$ increase compared to before industrialization (KMA, 2020), and this constant increase is expected to raise the average temperature of the Earth by $4-5^{\circ} \mathrm{C}$ (Xu et al., 2020).

The increase in atmospheric carbon concentration is caused by industrialization as well as excessive use of fossil fuels and reduction of greenspace (Jo et al., 2019a). To reduce carbon concentration, it is necessary to take techni-

This study is developed based on parts of the doctoral dissertation by Kim(2021).

Received: February 10, 2021, Revised: March 1, 2021, Accepted: March 11, 2021

First author: Jin-Young Kim, jykim84@kangwon.ac.kr, (B) https://orcid.org/0000-0003-0820-7412

*Corresponding author: Hyun-Kil Jo, jhk@kangwon.ac.kr, (1D https://orcid.org/0000-0003-1629-4405 
cal measures such as minimizing consumption of fossil fuels and developing and increasing supply of alternative energy resources, as well as to maintain and expand carbon sinks by establishing various types of greenspace and managing them efficiently. Urban trees planted in the streets, gardens, and parks absorb and store atmospheric carbon in their growth process and contribute to carbon accumulation of soil (Jo et al., 2020b). In particular, street trees perform a key role in reducing the concentrations of carbon emissions from vehicles, being closest to their direct and indirect sources. According to Korea Forest Service (2020), the national road length is $105,947 \mathrm{~km}$ as of 2018 , and street trees are planted on only $41 \%$. In other words, street space is a potentially important space that can promote carbon reduction capacity by planting new street trees in the limited urban space.

Studies in Korea and overseas on carbon uptake in greenspace of streets (Jo and Cho, 1998; Jo, 1999; Jo et al., 2003; Park and Kang, 2010; Kim et al., 2011; Kim, 2013; Russo et al., 2015; Park, 2015a; Park, 2015b; Tang et al., 2016; Jo et al., 2018; Zhao et al., 2018) have been conducted since the late 1990s. Recently, Jo (2020) and Jo et al. (2020b) have quantified the carbon uptake of street trees in some cities of Korea and provided planting guidelines to maximize it. However, studies in Korea thus far merely provided results limited mostly to big cities or parts of Gangwon-do, or applied methods using satellite image instead of field survey, and thus research data on street trees by city and region is still limited. To investigate the carbon reduction capacity of street trees at the urban and regional level and increase their effects, further research is necessary based on field survey in addition to securing various city samples. Therefore, the purpose of this study is to quantify carbon uptake and storage of urban street trees in some small and medium-sized cities and provide methods to improve planting of street trees to promote carbon reduction capacity. In this study, carbon uptake refers to the amount of carbon captured by trees for a year, and carbon storage refers to the total amount captured and stored by trees over time growth.

\section{Research Methods}

\section{Selection of study cities and street spaces}

The study cities were selected among those without research on street trees and carbon, considering the national and regional distribution of the city in previous studies (Jo, 1999; Jo et al., 2003; Park and Kang, 2010; Park, 2015b; Jo et al., 2018, 2020b; Jo, 2020). Provinces without domestic research on carbon were Chungbuk, Jeonbuk, Gyeongnam, and Jeju. We first considered the cities of Chungbuk and Jeonbuk that are relatively close to Chuncheon where the researchers reside seleted, considering the efficiency of research such as time and costs required for field survey. We selected Chungju out of the three cities in Chungbuk (Cheongju, Chungju, Jecheon) considering the population and location, and Jeonju out of the cities in Jeonbuk at the heart of the province where the provincial capital is located. Furthermore, we also selected Sejong to compare the differences in carbon uptake capacity between old towns and a new town according to tree size, vertical structure, and growth conditions.

We selected total 155 sites including 51 in Sejong, 47 in Chungju, and 57 in Jeonju through systematic sampling on the 1:1,000 scale aerial photographs (Fig. 1). Sampling was conducted with reference to the method by Jo et al. (2018, 2020a) and Jo (2020). The sampling method applied to this study is designed to reflect various street environments and street tree species in each city as much as possible considering the size of the city and layout of the road network. We drew radial lines in 8 directions around the cities and rings at $10 \mathrm{~cm}$ intervals, sampling all their interfaces. Streets were limited to those within the city by use district. The aerial photographs used in this study were aerial orthoimages provided by the National Geographic Information Institute, and those for Chungju and Sejong were taken in 2016 and for Jeonju taken in 2018. The sites included roads with at least two lanes as well as a sidewalk, median strips, and traffic islands. 


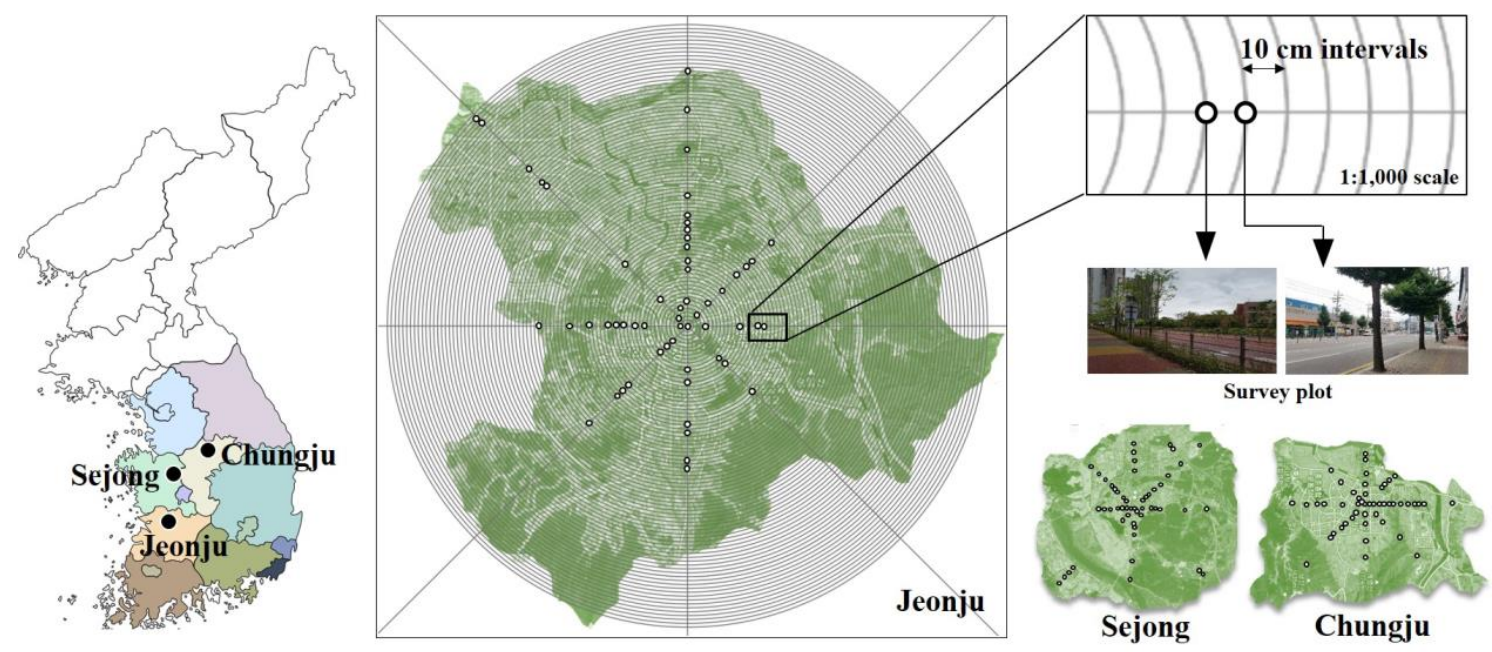

Fig. 1. Location of the study cities and systematic sampling method used in this study.

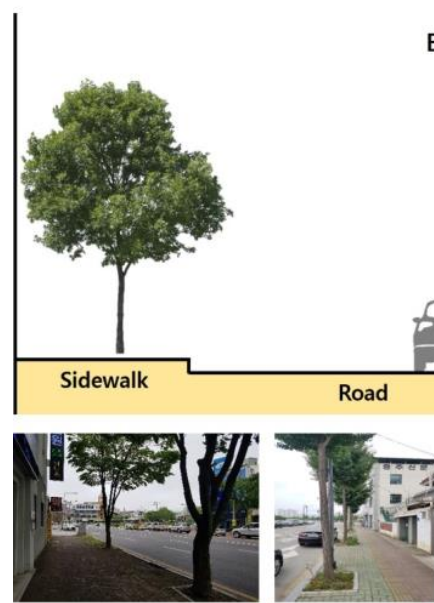

Horizontal
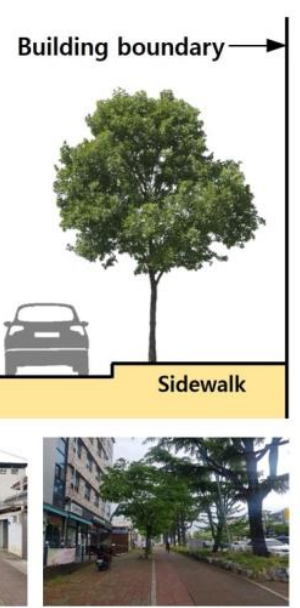

(1)

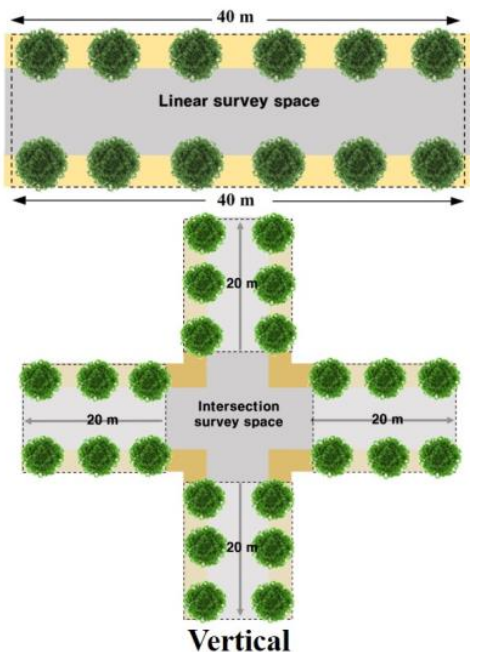

Fig. 2. Horizontal and vertical survey boundary in this study.

\section{Survey of the street environment and tree planting structure}

We surveyed the street environment and planting structure through on-site surveys of total 155 sites for 2 years in 2019-2020. We examined tree species and their horizontal and vertical structures including diameter at breast height (DBH), diameter at root collar (DRC), tree height, crown width, population, and layer, as well as the street environment such as the number of lanes, sidewalk width, and planter width on each site. The site was set vertically up to $80 \mathrm{~m}$ with $40 \mathrm{~m}$ each from the sample point, and horizontally up to the building boundary of the sidewalk including the road (Jo et al., 2018; 2020b) (Fig. 2). Based on the data, we analyzed the street environment status, tree density and cover, DBH structure, important percentage, and vertical structure of each site. The data was used to calculate the carbon uptake and storage of each point.

\section{Calculation of carbon uptake and storage}

Carbon uptake and storage of street trees may be different from that of forest trees due to the differences in the street environment, green area structure, and management. Therefore, this study calculated the carbon uptake and storage of street trees by applying the quantification model 
for each tree species developed for urban landscape trees including street trees (Jo and Cho, 1998; Jo, 2001, 2002; Jo and Ahn, 2001, 2012; Jo et al., 2013, 2014, 2019b, Jo, 2020). In other words, we applied the quantification model developed by $\mathrm{CO}_{2}$ exchange rate measurement or the direct harvesting method of urban landscape trees using DBH or DRC as the independent variable to calculate the carbon uptake and storage per tree and unit area. For some tree species where the quantification model could not be obtained, we applied a different quantification model for deciduous and evergreen trees developed based on the aforementioned model (Jo, 2020). Based on the calculated carbon uptake and storage per tree and unit area, we determined the total plantation status of street trees nationwide and by city and calculated the total annual carbon uptake and storage.

\section{Results and Discussion}

\section{Cities and street environments}

The total area of streets was 1,517 (Jeonju)-2,926 (Sejong) ha depending on the city (KOSIS, 2020). As a result of examining the street environments most streets were closest to neighborhood living facilities for roadside land use in all cities (37.0-69.1\%), followed by streets near residential areas (12.7-31.4\%), streets near greenspace (8.5-31.4\%), and others (industrial area, farmland, etc.; 0.2-5.5\%). Road width was minimum 6-maximum $24 \mathrm{~m}$ and average $14.8 \pm 0.3 \mathrm{~m}$. Sidewalk width was minimum 1-maximum $10 \mathrm{~m}$ and average $3.9 \pm 0.1 \mathrm{~m}$, and in sections with narrow sidewalks, there were no street trees planted at all, or it was impossible to plant any.
For street trees planting spacewere $1.1 \mathrm{~m}^{2} /$ tree in Chungju and Jeonju. Currently, street trees are planted by digging holes after the roads and sidewalks are all paved, which makes it actually difficult to provide planting spaces and soil environments necessary for normal growth of street trees. It would be desirable to improve the planting order of street trees in making street plans for new towns and cities (securing planting spaces $\rightarrow$ planting street trees $\rightarrow$ paving sidewalk) so that the adequate planting spaces and soil environments are provided for normal growth of street trees, thereby promoting various benefits including carbon uptake of street trees. Furthermore, roots of street trees are distributed widely and horizontally rather than deeply and vertically (Jo and Park, 2017), and thus it is necessary to secure sufficient planting width and breadth necessary for the growth of street trees by stipulating the band-type planting standards. Meanwhile, approximately $82.1 \%$ of all study sites in Sejong adopted band-type planting. The spacing of street trees were minimum 3-maximum $13 \mathrm{~m}$ and average $7.1 \pm 0.1 \mathrm{~m}$, with most street trees planted in one row.

\section{Horizontal and vertical structure of street trees}

The tree density of street trees was 1.1 (Chungju and Jeonju)-1.2 trees $/ 100 \mathrm{~m}^{2}$ (Sejong) depending on the city (Table 1), and average $1.1 \pm 0.0$ trees $/ 100 \mathrm{~m}^{2}$. Unlike other greenspace such as parks and gardens, street planting is carried out based on spacing, and thus the density was similar among the cities without a significant difference $(P>.05)$. The cover of street trees including both shrubs and trees was 3.7 (Sejong)-9.3\% (Jeonju) depending on the city, and average $6.6 \pm 0.5 \%$. Sejong, where the cover was remarkably lower than other cities, mostly had new street

Table 1. Street tree planting structures in study cites

\begin{tabular}{ccccc}
\hline City & Density & Cover $^{*}$ & \multicolumn{2}{c}{ Vertical Structure (\%) } \\
\cline { 3 - 5 }$\left(\right.$ no. $\left./ 100 \mathrm{~m}^{2}\right)$ & $(\%)$ & $3.74 \pm 0.34$ & Single-layer & Multi-layer \\
\hline Sejong & $1.22 \pm 0.06$ & $6.21 \pm 0.47$ & 93.5 & 6.0 \\
Chungju & $1.07 \pm 0.06$ & $9.34 \pm 1.47$ & 47.1 & 52.9 \\
Jeonju & $1.12 \pm 0.04$ & $6.56 \pm 0.47$ & - & - \\
Mean & $1.14 \pm 0.03$ & & \\
\hline
\end{tabular}

\footnotetext{
${ }^{*}$ It includes shrubs
} 
trees planted in 2012-2013, with the average crown width about $1 / 3-1 / 2$ of trees in other cities. The street tree cover in some cities of the United States was approximately 14\% (Maco and McPherson, 2002). In comparison, the cover of street trees in this study is approximately 53\% lower, which is due to size, relatively small planters, and differences in street environments due to the high-tension wires and communication lines a the top of the tree crowns. Meanwhile, the street tree cover of some cities in Korea was approximately $12.5 \%$ (Jo et al., 2020b), indicating that the street tree cover in this study is about $47.5 \%$ of the cities in previous studies.

The DBH was 10.6 (Sejong)-23.9 cm (Jeonju) depending on the city, and average $17.2 \pm 0.8 \mathrm{~cm}$ (Table 2). The DBH distribution in Chungju and Jeonju was 46.4-61.1\% below $20 \mathrm{~cm}$ and $77.3-87.7 \%$ below $30 \mathrm{~cm}$, whereas that in Sejong was $98.2 \%$ under $20 \mathrm{~cm}$, indicating that most trees are in the growth process. It is reported that the tree DBH in Italy and China is 23.1-34.9 cm (Russo et al., 2015; Tang et al., 2016). In comparison, the average DBH of street trees in this study was $49.3-74.5 \%$ lower. The tree species within the top 10 based on the importance values by study cities were Zelkova serrata, Gingko biloba, Chionanthus retusus, Acer palmatum, Rhododendron yedoense var. poukhanense, and Buxus microphylla var. koreana. These are common tree species planted in the cities of Korea, and carbon uptake capacity of Zelkova serrata is relatively higher than others, whereas that of Gingko biloba is lower (Jo and Park, 2017).

For the vertical structure by city (Table 1), the percentage of the multi-layer structure in which trees, shrubs, and herbs are planted together was 52.9-86.0\% in Sejong and Jeonju, which was higher than the percentage of the single-layer structure in which only trees or shrubs are planted. In Chungju, the percentage of the multi-layer structure was approximately $6.5 \%$, which was much higher than that of the single-layer structure. The single-layer structure mostly lacked planting of shrubs. For cities where street trees are already planted, while it is also necessary to make structural improvements by securing sidewalk and planter width as well as planting spaces by reducing unnecessary lanes to promote carbon reduction capacity of street trees, it may be more efficient to implement highdensity multi-layer planting and active tree plantation within potential planting spaces considering the time and costs as well as the street environment. According to this study, by actively planting trees in plantable spaces by changing the single-layer to multi-layer structure and band-type planting, it will be possible to uptake about 1.3 times more carbon.

\section{Carbon uptake and storage}

The carbon uptake per street tree in the study cities was 3.2 (Sejong)-12.8 kg/tree/year (Jeonju) depending on the city, and average $7.2 \pm 0.6 \mathrm{~kg} /$ tree/year(Table 3). The carbon storage per street tree was $23.9-146.2 \mathrm{~kg} /$ tree depending on the city, and average $87.1 \pm 10.2 \mathrm{~kg} /$ tree. The average carbon uptake and storage per urban landscape tree including Pinus densiflora, Zelkova serrata, Acer palmatum, Prunus yedoensis, and Gingko biloba with the DBH of $20 \mathrm{~cm}$ was $7.6 \mathrm{~kg} /$ tree/year and $80.8 \mathrm{~kg} /$ tree (Jo and Ahn, 2012; Jo et al., 2013), indicating that the carbon uptake of the street trees in this study was similar to previous studies, whereas carbon storage was slightly higher.

The carbon uptake per unit area was 0.4-1.4 ton/ha/year in the study cities, and average $0.8 \pm 0.1$ ton/ha/year. The carbon storage per unit area was 2.9-17.5 ton/ha depending on the city, and average $10.0 \pm 1.0$ ton/ha throughout all cities (Table 3). The average carbon storage per unit area by trees planted in the streets of Korea was 0.6 ton/ha/year (Jo et al., 2020a), showing that the cities in this study were

Table 2. DBH distribution of street trees in study cities

\begin{tabular}{|c|c|c|c|c|c|}
\hline \multirow{2}{*}{ City } & \multirow{2}{*}{ Mean DBH $(\mathrm{cm})$} & \multicolumn{4}{|c|}{ DBH distribution (\%) } \\
\hline & & $<20 \mathrm{~cm}$ & $20-30 \mathrm{~cm}$ & $30-40 \mathrm{~cm}$ & $\geq 40 \mathrm{~cm}$ \\
\hline Sejong & $10.6 \pm 0.4$ & 98.2 & 0.9 & 0.9 & 0.0 \\
\hline Chungju & $18.4 \pm 0.8$ & 61.1 & 26.6 & 10.6 & 1.6 \\
\hline Jeonju & $23.9 \pm 1.2$ & 46.4 & 30.9 & 16.6 & 6.1 \\
\hline
\end{tabular}


Table 3. Carbon Uptake and storage by street trees and shrubs planted in study cities

\begin{tabular}{cccccc}
\hline \multirow{2}{*}{ City } & \multicolumn{2}{c}{ Carbon Uptake } & & \multicolumn{2}{c}{ Carbon Storage } \\
\cline { 2 - 3 } \cline { 5 - 6 } & $\begin{array}{c}\text { Per street trees } \\
(\mathrm{kg} / \text { tree } / \mathrm{yr})\end{array}$ & $\begin{array}{c}\text { Per street area } \\
\text { (ton/ha/yr) }\end{array}$ & & $\begin{array}{c}\text { Per street trees } \\
(\mathrm{kg} / \text { tree })\end{array}$ & $\begin{array}{c}\text { Per street area } \\
(\text { ton } / \mathrm{ha})\end{array}$ \\
\hline Sejong & $3.23 \pm 0.36$ & & & $23.94 \pm 3.75$ & $2.94 \pm 0.24$ \\
Chungju & $5.41 \pm 0.54$ & $0.57 \pm 0.03$ & & $88.76 \pm 13.40$ & $9.25 \pm 1.40$ \\
Jeonju & $12.77 \pm 1.27$ & $1.40 \pm 0.13$ & & $146.17 \pm 23.87$ & $17.49 \pm 2.36$ \\
Mean & $7.23 \pm 0.59$ & $0.79 \pm 0.06$ & & $87.08 \pm 10.20$ & $9.95 \pm 1.04$ \\
\hline
\end{tabular}

approximately 1.3 times higher. Meanwhile, according to a similar study overseas, the carbon uptake per unit area of streets in Beijing, China was average 1.3 ton/ha/year (Tang et al., 2016). In comparison, the average annual carbon uptake of the street trees in this study was approximately $39 \%$ lower.

The high and low of the annual carbon uptake are due to the differences in the density, size, vertical structure, and tree species (Jo et al., 2019a, 2020a, 2020b). In Jeonju, the annual carbon uptake per street tree was at least 2.4 times greater than other cities in this study, which is also due to the aforementioned reasons. In other words, Jeonju had 1.3-2.3 times higher average DBH than other cities in this study, and the ratio of the multi-layer structure in the streets was higher than that of the single-layer structure. Moreover, it had a comparatively higher percentage of Zelkova serrata (Jo and Ahn, 2012; Jo and Park, 2017) with relatively high carbon absorbing capacity. According to a previous study (Jo and Ahn, 2012), the carbon uptake per tree of Zelkova serrata with the DBH of $20 \mathrm{~cm}$ was $12.1 \mathrm{~kg} /$ tree/year, which was about twice that of Gingko biloba that is frequently planted as a street tree. It is difficult to select the species for street trees in the right time and the right place due to constraints of climate, street environment, and supply of street tree species. Therefore, it is necessary to promote the diversity of street tree species and carbon uptake capacity by operating a street tree nursery led by each local government and producing trees that are suitable for each cities environment and that also have high carbon uptake capacity.

Sejong had relatively higher percentages of the multi-layer structure and band-type planting than other cities, but it also had a higher percentage of population showing poor growth. Poor growth results in poor carbon uptake as well, and thus measures are required such as creating adequate grounds for growth and effectively managing the trees after planting. According to this study, trees that showed normal growth had about 1.4 times greater crown volume than others even if they were in the same size (Gingko biloba DBH $15 \mathrm{~cm}$ ). Total carbon uptake and storage of street trees by city was 49.8 ton/year and 3,441.0 ton in Sejong, 268.3 ton/year and 8,683.9 ton, in Chungju, and 817.7 ton/year and 10,612.9 ton in Jeonju, adding up to total $1,135.8$ ton/year and 22,737.8 ton. The annual carbon emission from one vehicle is approximately 0.5 ton/year (KEA, 2020), which means that the urban street trees in this study performed a significant role in offsetting carbon produced by about 100 (Sejong)-1,635 (Chungju) vehicles every year. Meanwhile, the total area of potential planting spaces and spaces without street trees in the cities was approximately 2,716 ha, indicating that by actively planting shrubs and trees in these plantable spaces, it will be possible to additionally carbon absorb about 1,818 ton/year.

\section{Conclusion}

Reducing carbon and slowing down climate change, which are major environmental concerns of this era, can be done by reducing use of fossil fuels, developing alternative energy resources, preventing forest damages, and planting trees. Streets can contribute to carbon reduction through tree planting in the city that lacks greenspace, but there is still insufficient research on the topic, which is why this study was conducted to obtain relevant data. In this study, we selected three small and medium-sized cities (Sejong, Chungju, Jeonju) that lack carbon-related research as the samples, quantified the carbon uptake and storage 
of urban street trees, and built data based on street trees to determine the carbon reduction effects.

The average carbon uptake and storage per street tree in this study was $7.2 \pm 0.6 \mathrm{~kg} /$ tree $/$ year and $87.1 \pm 10.2$ $\mathrm{kg} /$ tree. Jeonju had at least 2.4 times more annual carbon uptake per tree compared to other cities, which is due to the differences in the size of trees, vertical structure, and tree species. On the other hand, Sejong showed relatively lower carbon uptake capacity than others despite the high percentages of the multi-layer structure and band-type planting, which is due to the high ratio of trees showing poor growth in addition to the aforementioned reasons, thereby having an unfavorable effect on carbon uptake as well. Based on the calculated carbon uptake per street tree, the urban street trees in this study performed a significant role in offsetting carbon produced by driving 2,272 vehicles a year.

To promote carbon reduction capacity of street trees, it is necessary to create a desirable planting space from the construction phase, plant tree species with favorable growth rates and relatively high carbon uptake capacity, and adopting the high-density multi-layer structure as much as possible instead of planting small trees in low density. Therefore, it is desirable to create planting spaces and soil environments in which street trees can grow normally by improving the planting order of street trees when making street plans for new cities and towns, while also extending the planting space in length, thereby increasing various benefits including carbon uptake of street trees. Furthermore, it is necessary to promote the diversity of street tree species and carbon uptake capacity by operating a street tree nursery led by each local government and producing trees that are suitable for each city's environment and that also have high carbon uptake capacity. For old towns where street trees are already planted, it is desirable to implement high-density multi-layer planting and active tree plantation within potential planting spaces considering the time and costs as well as the street environment.

This study has significance in providing the basic unit to quantify carbon reduction capacity based on field surveys when there is insufficient research on carbon uptake of street trees. The results can be used to make planting plans to promote carbon uptake at the national level in addition to the cities studied here, or applied to laws related to street trees by Korea Forest Service, the Ministry of Land, Infrastructure, and Transport, and local governments to establish relevant systems on site. This study has limitations in that it failed to conduct a complete enumeration of street trees in each city due to lack of human resources, cost and time required, and that the subjects were limited to three cities. It is necessary to comprehensively investigate the carbon reduction capacity of street trees in Korea by extending research with samples from various inland and coastal cities and establish the optimum planting plans for each type of street environment that can represent the carbon reduction capacity of each tree species.

\section{References}

Jo, H.K. 1999. Carbon uptake and emissions in urban landscape, and the role of urban greenspace for several cities in Kangwon Province. J. Korean Inst. Landsc. Archit. 27(1):39-53.

Jo, H.K. 2001. Indicator for $\mathrm{CO}_{2}$ uptake and atmospheric purification evaluation of vegetation. development of eco-indicators for sustainable development. Research Report to Ministry of Environment.

Jo, H.K. 2002. Impacts of urban greenspace on offsetting carbon emissions for middle Korea. J. Environ. Manag. 64(2):115-126. https://doi.org/10.1006/jema.2001.0491

Jo, H.K. 2020. Development of model and technology for establishment, management and evaluation of urban forests in living zone to improve carbon sequestration sources and multi-dimensional benefits against new climate change regime. Research Report to Korea Forest Service. https://www.konetic.or.kr/ecoservice/development_vie w.asp?1=1\&gotopage=1\&unique_num $=3397$

Jo, H.K. and D.H. Cho. 1998. Annual $\mathrm{CO}_{2}$ uptake by urban popular landscape tree species. J. Korean Inst. Landsc. Archit. 26(2):38-53.

Jo, H.K. and H.M. Park. 2017. Changes in growth rate and carbon sequestration by age of landscape trees. J. Korean Inst. Landsc. Archit. 45(5):97-104. https://doi.org/10.9715/KILA.2017.45.5.097

Jo, H.K. and T.W. Ahn. 2001. Annual $\mathrm{CO}_{2}$ uptake and 
atmospheric purification by urban coniferous trees -For Pinus densiflora and Pinus koraiensis. Korean J. Environ. Ecol. 15(2):118-124.

Jo, H.K. and T.W. Ahn. 2012. Carbon storage and uptake by deciduous tree species for urban landscape. J. Korean Inst. Landsc. Archit. 40(5):160-168. https://doi.org/10.9 715/KILA.2012.40.5.160

Jo, H.K., H.M. Park, and J.Y. Kim. 2020a. Carbon reduction and enhancement for greenspace in institutional lands. J. Korean Inst. Landsc. Archit. 48(4):1-7. https://doi.org/10.9715/KILA.2020.48.4.001

Jo, H.K., J.Y. Kim, and H.M. Park. 2013. Carbon storage and uptake by evergreen trees for urban landscape -For Pinus densiflora and Pinus koraiensis. Korean J. Environ. Ecol. 27(5):571-578. http://dx.doi.org/ 10.13047/KJEE.2 013.27.5.571

Jo, H.K., J.Y. Kim, and H.M. Park. 2014. Carbon reduction effects of urban landscape trees and development of quantitative models -For five native species. J. Korean Inst. Landsc. Archit. 42(5):13-21. http://dx.doi.org/10.97 15/KILA.2014.42.5.013

Jo, H.K., J.Y. Kim, and H.M. Park. 2018. Carbon storage and uptake by street trees in Seoul. J. For. Environ. Sci. 34(2):162-164. https://doi.org/10.7747/JFES.2018.34.2.162

Jo, H.K., J.Y. Kim, and H.M. Park. 2019a. Carbon reduction and planning strategies for urban parks in Seoul. Urban For. Urban Green. 41:48-54. https://doi.org/10.1016/j.uf ug.2019.03.009

Jo, H.K., J.Y. Kim, and H.M. Park. 2019b. Carbon reduction services of evergreen broadleaved landscape trees for Ilex rotunda and Machilus thunbergii in Southern Korea J. For. Environ. Sci. 35(4):240-247. https://doi.org/ 10.7747/JFES.2019.35.4.240

Jo, H.K., J.Y. Kim, and H.M. Park. 2020b. Carbon and $\mathrm{PM}_{2.5}$ reduction and design guidelines for street trees in Korea. sustainability 12(24):10414. https://doi.org/10. 3390/su122410414

Jo, H.K., T.W. Ahn, and Y.H. Cho. 2003. Effects of urban greenspace on improving atmospheric environment. J. Korean Inst. Landsc. Archit. 31(3):83-90.

Kim, J.Y. 2021. Service of net carbon uptake by urban street trees and guidelines of planting and management. Doctoral dissertation, Kangwon National University, Chuncheon, Korea.
Kim, K.T., J.W. Cho, and H.H. Yoo. 2011. Carbon storage estimation of urban area using KOMPSAT-2 imagery. J. Korean Soc. Geospat. Inf. Sci. 19(2):49-54.

Kim, T.J. 2013. The species selection and planting guidelines for street tree to reduce road atmospheric carbon dioxide. J. Korean Inst. For. Recreat. 17(1):131-144. http://dx.doi.org/10.34272/forest.2013.17.1.014

Korea Forest Service. 2020. Manual of planing and management for street trees. Daejeon, Korea: Korea Forest Service. Retrieved from https://www.forest.go.kr/kfswe b/cop/bbs/selectBoardArticle.do?nttId=3147093\&bbsId $=$ BBSMSTR_1069\&pageUnit $=10 \&$ pageIndex $=1 \&$ searc htitle $=$ title \&searchcont $=\&$ searchkey $=\&$ searchwriter $=\& s$ earchWrd $=\&$ ctgryLrcls $=\&$ ctgryMdcls $=\&$ ctgrySmcls $=\&$ ntcStartDt=\&ntcEndDt=\&mn=NKFS_01_01\&orgId=

Korea Meteorological Administration (KMA). 2020, November 23. Global carbon dioxide concentration rises without brakes. Retrieved from https://www.kma.go.kr/notify/pr ess $/$ kma_list.jsp?bid $=$ press\&mode $=$ view\&num $=119394$ $6 \&$ page $=3 \&$ field $=\&$ text $=$

Korean Energy Agency (KEA). 2020, January 21. $\mathrm{CO}_{2}$ emissions by car. Retrieved from http://bpms.kemco.or. kr/transport_2012/car/car_choice.Aspx

Korean Statistical Information Service (KOSIS). 2020, January 21. Statistical Yearbook. Retrieved from http:// kosis.kr/statisticsList/statisticsListIndex.do?menuId=M 01_01\&vwcd=MT_ZTITLE\&parmTabId=M_01_01\#Se lectStatsBoxDiv

Maco, S.E. and E.G. McPherson. 2002. Assessing canopy cover over streets and sidewalks in street tree populations. J. Arboric. 28(6):270-276.

Ministry of Environment. 2016, January 15. Guide to the Paris agreement of the new climate system after the Kyoto protocol. Retrieved from http://www.me.go.kr/ho $\mathrm{me} / \mathrm{web} / \mathrm{board} / \mathrm{read} . \mathrm{do}$ ?menuId=10181\&boardId $=6561$ 90\&boardMasterId $=54$

Park, E.J. and K.Y. Kang. 2010. Estimation of C storage and annual $\mathrm{CO}_{2}$ uptake by street trees in Gyeonggi-do. Korean J. Environ. Ecol. 24(5):591-600.

Park. C.I. 2015a. A study on carbon dioxide absorption of street tree according to transplantation planting methods for Sorbus alnifolia. J. Environ. Sci. Int. 24(2): 253-260. https://doi.org/10.5322/JESI.2015.24.2.253

Park. M.W. 2015b. Study on the estimated carbon uptake 
of the city street trees and increase carbon uptake by improving species. Master's thesis, Hoseo University, Chungnam, Korea.

Russo, A., F.J. Escobedo, N. Timilsina, and S. Zerbe. 2015. Transportation carbon dioxide emission offsets by public urban trees: A case study in Bolzano, Italy. Urban For. Urban Green. 14(2):398-403. https://doi.org/10.1016/j.u fug.2015.04.002

Tang, Y., A. Chen, and S. Zhao. 2016. Carbon storage and sequestration of urban street trees in Beijing, China.
Front. Ecol. Evol. 4:1-8. https://doi.org/10.3389/fevo.20 16.00053

Xu, C., T.A. Kohler, T.M. Lenton, J.C. Svenning, and M. Scheffer. 2020. Future of the human climate niche. Proc. Natl. Acad. Sci. U.S. 117(21):11350-11355. https://doi.org /10.1073/pnas.1910114117

Zhao, Y., Q. Hu, H. LI, S. Wang, and M. Ai. 2018. Evaluating carbon sequestration and $\mathrm{PM}_{2.5}$ removal of urban street trees using mobile laser scanning data. Remote Sens. 10(11):1759. https://doi.org/10.3390/rs10111759 